\title{
Peripheral retinal ablation in the treatment of proliferative diabetic retinopathy during pregnancy
}

\author{
B. L. HERCULES, MARGARET WOZENCROFT, I. I. GAYED, AND \\ JULIE JEACOCK \\ From the Royal Eye Hospital, Computational Group, Faculty of Medicine, University of Manchester, \\ and Ahmadi Hospital, Kuwait Oil Company, Kuwait
}

SUMMARY The course of proliferative diabetic retinopathy involving the optic disc was followed, and the response to peripheral retinal photocoagulation monitored by argon laser in 11 patients during and after 13 pregnancies. Traditional obstetric practice assumes that pregnancy is a stimulus to irreversible progression of proliferative diabetic retinopathy, and that timely abortion and sterilisation are essential in order to achieve control of the neovascular process. Extensive photocoagulation will cause significant regression of neovascular complexes in $63 \%$ of cases, and it confers sufficient benefits to make ophthalmic indications for therapeutic abortion and sterilisation no longer tenable.

Taylor and Dobree ${ }^{1}$ stated that between 68 and $73 \cdot 25 \%$ of patients presenting with proliferative diabetic retinopathy have neovascularisation involving the optic disc. In a 3-year study Beetham et al. ${ }^{2}$ showed that $85 \%$ (28 patients) of untreated eyes with vitreous haemorrhage bled from new vessels at the optic disc. This group of patients, exhibiting neovascularisation of the optic disc, inevitably have the poorest prognosis. Consequent on haemorrhage one-third of involved eyes are blind and one-third have permanent impairment of vision within 1 year. $^{3}$ This is the most serious potential hazard for visual prognosis $;{ }^{4} 50 \%$ of these diabetic patients are blind within 2 to 3 years. If one eye becomes blind, Patz and Berkow ${ }^{5}$ have shown that the second (good) eye follows rapidly ( $50 \%$ within 1 year).

New vessels in proliferative diabetic retinopathy tend to progress during 9 months of activity in many cases, and it is therefore difficult to assess the effect of pregnancy on the course of this process. Reports on the subject come to no firm or convincing conclusions, but the risk to vision of rapidly advancing retinopathy during pregnancy has been stated to be high. Diabetic patients have frequently been advised against pregnancy if retinopathy has been present. ${ }^{6}$ From 200 pregnant diabetics attending the Joslin clinic with ocular symptoms Beetham ${ }^{7}$ found 12 patients (18 pregnancies) with proliferative retinopathy and observed progression of the neo-

Correspondence to Mr B. L. Hercules, FRCS, Manchester Royal Eye Hospital, Oxford Road, Manchester M13 9WH. vascular process in 4 . Janert et $a .^{8}$ observed progression of retinopathy in all 6 of their patients. White ${ }^{9}$ described 87 pregnant diabetics with proliferative retinopathy: 10 showed haemorrhagic activity prior to or during the first trimester; 11 of the 20 eyes progressed to blindness. She noted that eye lesions may improve after delivery, and that abortion is indicated (i) when retinopathy is deteriorating and (ii) when blindness might be expected if the pregnancy is continued. This tendency to regression of proliferative retinopathy after delivery has also been observed by Lawrence, ${ }^{10}$ Stephens et al.,11 Janert et al., ${ }^{8}$ and Laws et al. ${ }^{12}$

Driscoll and Gillespie ${ }^{13}$ considered advancing retinal neovascularisation, but not mere existence of retinopathy or blindness, an indication for termination of pregnancy. They also considered advanced retinopathy, and a high risk of ensuing blindness in the foreseeable future, constituted valid grounds for sterilisation.

Okun et al. ${ }^{14}$ noted that in 6 out of 10 diabetic patients proliferative retinopathy progressed rapidly during pregnancy. After termination the rate of growth of new vessels lessened, but they regressed in only 1 case. Burt and Weaver ${ }^{15}$ reported 2 cases of proliferative retinopathy in successfully pregnant women. One improved only after delivery, when pituitary ablation was undertaken, and the other improved during the course of pregnancy. They concluded that patients should be managed individually rather than routinely recommended for therapeutic abortion. Kohner et al ${ }^{16}$ demonstrated that rapidly advancing proliferative retinopathy 
could be contained during pregnancy by photocoagulation and afterwards by pituitary ablation.

In view of the suggestions of other workers and before any of their results were available a trial was initiated in Manchester in 1973 to attempt elimination of optic-disc neovascularisation in the diabetic patient by peripheral retinal ablation. ${ }^{17}$ During the course of this study 5 pregnant women were admitted and every attempt was made to contain the proliferative process during their 6 pregnancies. Subsequently 6 more pregnant patients with optic disc neovascularisation were admitted to the group to give a total of 11 women and 13 pregnancies.

\section{Patients and methods}

Five pregnant women were entered into a randomised, controlled trial of 94 consecutive patients with a reasonably symmetrical proliferative diabetic retinopathy involving the optic disc. They had a visual acuity which did not differ by more than 2 lines on the Snellen chart and was at least 6/24 in the worse eye. Subsequently a further 6 women with optic disc neovascularisation were grouped with the women from the controlled trial. This latter group either were receiving argon laser photocoagulation when they discovered they were pregnant or commenced treatment soon after this event. No patient was excluded from the study for any of the reasons laid down in the study protocol. ${ }^{17}$

\section{TECHNIQUE}

All treated eyes were subjected to extensive peripheral retinal photocoagulation by means of a Coherent 800 gas-argon laser, incorporating a 3 mirror Goldmann lens in the delivery system ${ }^{18}$ when necessary. The procedure was well tolerated after instillation of local anaesthetic drops in all patients.

Photocoagulation burns were applied within the vascular arcades above and below the macula, but an approximately circular area of radius $2 \frac{1}{2}$ disc diameters, with the fovea at its centre and including the papillomacular bundle, was left untouched. In the nasal fundus photocoagulation was extended centrally to the edge of the optic disc and involved any new vessels arising from this margin. In all meridians photocoagulation was extended anteriorly to the equator by means of the 3-mirror lens.

Individual burns with sufficient energy to accomplish minimal retinal blanching were applied so that the observer achieved a uniform response over the whole area being treated. Marker burns of $200 \mu \mathrm{m}$ diameter were applied to delineate the central area which was to be avoided. Inside the vascular arcades the $200 \mu \mathrm{m}$ spot diameter was used. Outside the arcades and nasally, the $500 \mu \mathrm{m}$ spot diameter was used exclusively as far as the periphery. In the nasal sector burns were applied from the nasal edge of the optic disc to the equator in radial rows which followed the direction of the nerve fibres.

Energy levels between 0.2 and 0.6 watt were used, though most burns required 0.35 to 0.45 watt. Inferiorly higher energy levels were required than in any other area of the retina. Lower energies of 0.2 watt were almost invariably adequate within the macular vascular arcades of vessels, where the 200 $\mu \mathrm{m}$ spot was used. In other areas utilising the $500 \mu \mathrm{m}$ spot levels up to 0.5 watt were usually required. To complete treatment over 2000 burns were applied to most patients (range 800 to 3000). The procedure usually required up to 6 sittings over a week.

Retreatment of areas which appeared unduly lightly treated and of any patches of untreated retina within the 'target' area of the ablation procedure was undertaken in patients in whom optic disc neovascularisation persisted.

\section{DATA RECORDED}

Patients entering the trial received a full ophthalmic assessment including refraction, tonometry, visual fields, fundus photography, and fluorescein angiography. Patients were not excluded from the study group on the basis of nephropathy or other serious extraocular diabetic problems. However, during and after treatment every attempt was made to achieve good diabetic control by careful medical assessment. The eye to be treated was chosen at random and the untreated eye recorded as a control.

Evaluation of treatment was based on four main criteria: (1) Visual acuity: best corrected visual acuities were obtained at each visit, on subjective testing, by a refractionist who was not aware of the previous visual acuity nor the treated eye. (2) Appearance of the optic discs 6 months after treatment and yearly from that point. Assessment was aided by colour photographs and fluorescein angiograms. (3) Vitreous haemorrhage and other complications including uveitis, glaucoma, and retinal detachment. (4) Blindness: eyes were accepted as blind as an end result of the proliferative process and/or vitreous haemorrhage if this involved a fall of visual acuity to less than $6 / 60$ on the Snellen chart. This result had to be recorded on at least two consecutive visits.

Patients were reviewed at intervals of 2 weeks, 1 month, and 4 to 6 months after the completion of peripheral retinal ablation. Further assessment included visual fields, retinal colour photography, and fluorescein angiography. 


\section{Results}

For the purposes of the study the 11 pregnant patients were compared with the nonpregnant women contained in the randomised, controlled trial of peripheral retinal ablation. ${ }^{17}$ Exclusions from the study were made if the patient conformed to one of the following criteria: (i) postmenopausal, at first attendance with proliferative retinal changes; (ii) pregnancy had occurred since proliferative retinal changes were first identified but prior to assessment in our clinic.

Finally the 2 groups of women were compared with all the men entered into the initial randomised, controlled study. The findings are shown in Table 1.

Table 1 Population studies of patients in comparative groups

\begin{tabular}{llll}
\hline & \multicolumn{2}{l}{ Women } & \multirow{2}{*}{ Men } \\
\cline { 2 - 3 } & Pregnant & Nonpregnant & \\
\hline $\begin{array}{l}\text { Age (mean) in years } \\
\text { Duration of diabetes (years) }\end{array}$ & 26 & 36.5 & 42 \\
$\begin{array}{l}\text { (i) mean } \\
\text { (ii) range }\end{array}$ & $17 \cdot 73$ & $17 \cdot 0$ & 18.45 \\
& $10 \rightarrow 25$ & $8 \rightarrow 32$ & $2 \rightarrow 40$ \\
\hline
\end{tabular}

\section{OPTIC DISC NEOVASCULARISATION}

Regression of new vessels at the optic disc was assessed on the basis of status at initial examination and subsequent change recorded $6 / 12$ after completion of photocoagulation, ${ }^{17}$ or, in the case of the pregnant women, 6/12 after the end of the gestational period (Figs. 1-6).

In the pooled female groups all patients experienced a measurable degree of vessel regression, while the male group had $7 \cdot 4 \%$ of cases in which the neovascular situation either remained stable or deteriorated. A less than significant response was measured in $36.4 \%$ of pregnant women, $33 \%$ of nonpregnant, and $9.2 \%$ of men. A significant improvement in vessel status was recorded in $63.6 \%$ of pregnant women, $66 \%$ of nonpregnant, and $83 \%$ of men (Table $2 a, b$ ).

Table 2a Initial grading of retinopathy at optic disc (according to classification of Hercules et al. ${ }^{17}$ )

\begin{tabular}{ccccc}
\hline & \multicolumn{3}{l}{ Total number of patients in grade } \\
\cline { 2 - 5 } & Pregnant & Nonpregnant & Males \\
\hline Grade & 1 & 3 & 12 & 21 \\
& 2 & 6 & 5 & 29 \\
& 3 & 2 & 4 & 4 \\
Total & 11 & 21 & 54 \\
\hline
\end{tabular}

Table 2b Percentage regression of new vessels at optic disc $(<50 \%$ is considered to be nonsignificant $)$

\begin{tabular}{llll}
\hline \multirow{2}{*}{ Vessel regression } & \multicolumn{3}{l}{ Total number of patients } \\
\cline { 2 - 4 } & Pregnant & Nonpregnant & Males \\
\hline $100 \%$ & 2 & 8 & 19 \\
$>50 \%$ & 5 & 6 & 25 \\
$<50 \%$ & 4 & 7 & 5 \\
Same or advancing & 0 & 0 & 4 \\
\hline
\end{tabular}

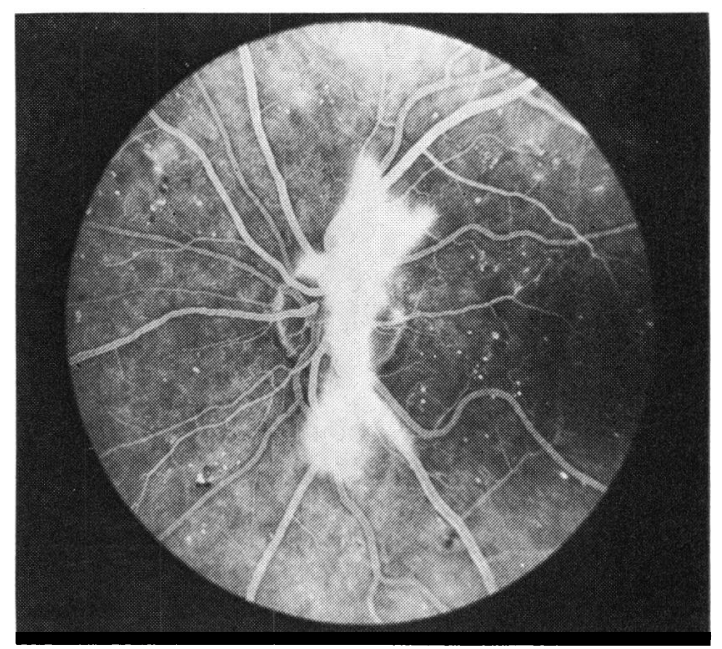

Fig. 1 Fluorescein angiogram showing early papillovitreal neovascularisation of the disc at the end of the first trimester of pregnancy.

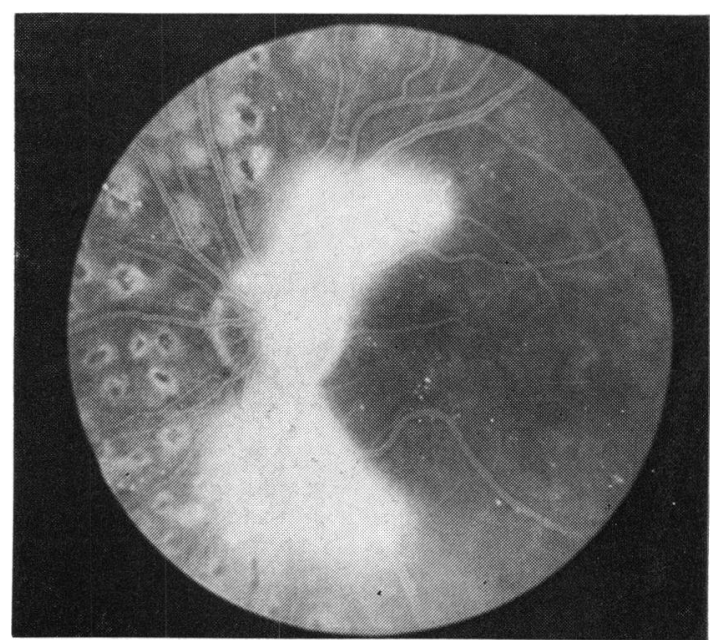

Fig. 2 Fluorescein angiogram of the fundus in Fig. 1 at 28 weeks. Peripheral retinal photocoagulation has been undertaken. Laser scars are either 1 or 12 weeks old. There has been an increase in new vessels along the temporal arcades. 
VITREOUS HAEMORRHAGE

The mean time to vitreous haemorrhage, and the occurrence of this event, were recorded in both treated and control eyes. The results are shown in Table 3a, b.

In the randomised, controlled trial, the mean time to the onset of vitreous haemorrhage from the start of treatment was evaluated in treated and control eyes. The difference in mean time to vitreous haemorrhage, expressed in years, for all treated

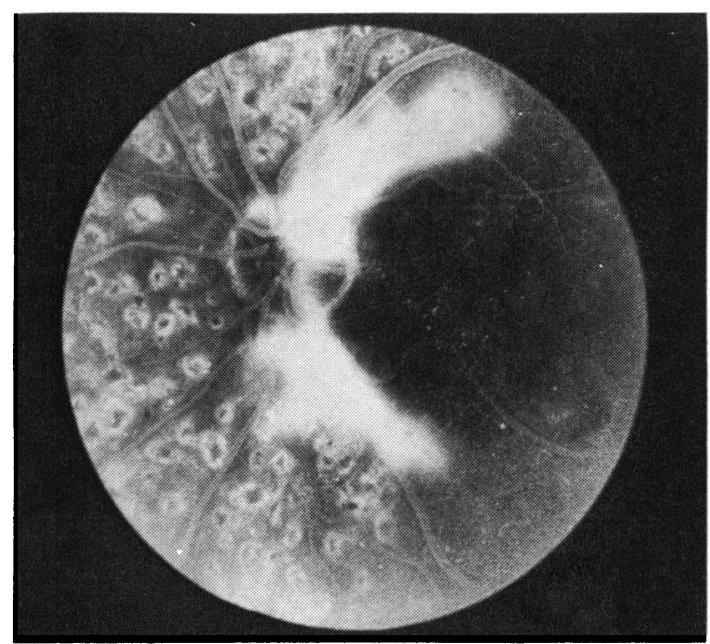

Fig. 3 Fluorescein angiogram shows the fundus of Fig. 16 months after the successful completion of pregnancy. There is no further advance of the 'arcuate' papillovitreal complex, and the vascular component is increasingly attenuated.

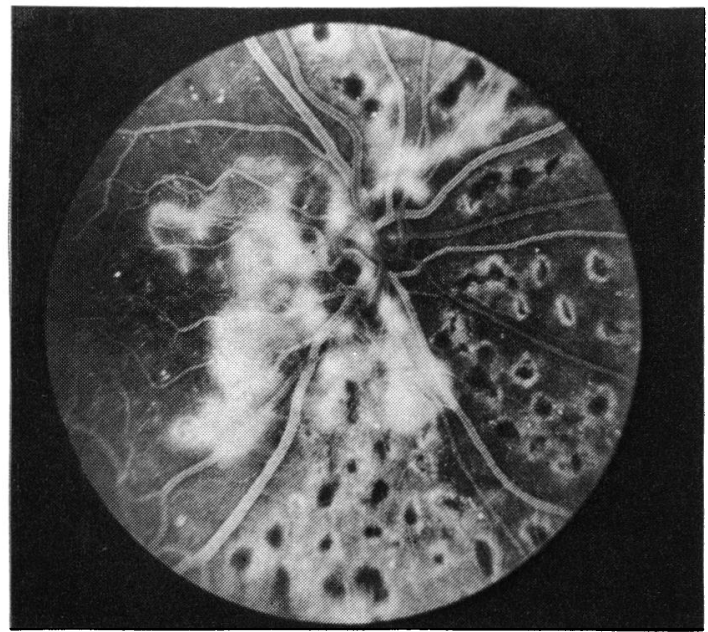

Fig. 5 Fluorescein angiogram showing the fundus of Fig. 4 with further argon laser applications in lightly treated and untreated areas at 28 weeks. There has been a slight extension of the neovascular complex. groups and for the control groups was very highly significant (Mann-Whitney $U$ test, $P<0.0001$ ).

\section{BLINDNESS}

Table 4 outlines the number of eyes in each of the 3 groups which proceeded to blindness within the first 3 years after photocoagulation.

In the randomised, controlled trial the difference in proportions between treated and control eyes

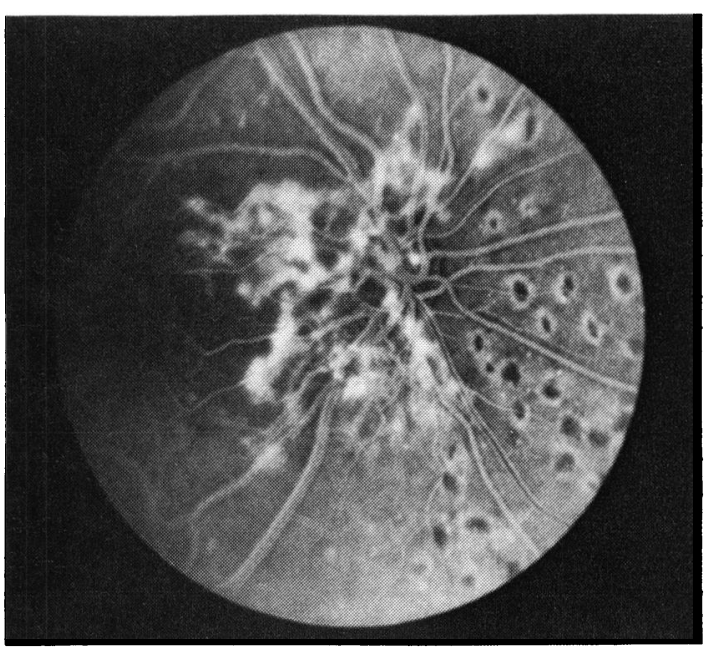

Fig. 4 Fluorescein angiogram showing extensive peripapillary neovascularisation with early glial tissue deposition after 12 weeks of pregnancy. Old argon laser burns are seen in the nasal fundus. This treatment was undertaken in the active phase of new vessel growth 3 weeks prior to pregnancy.

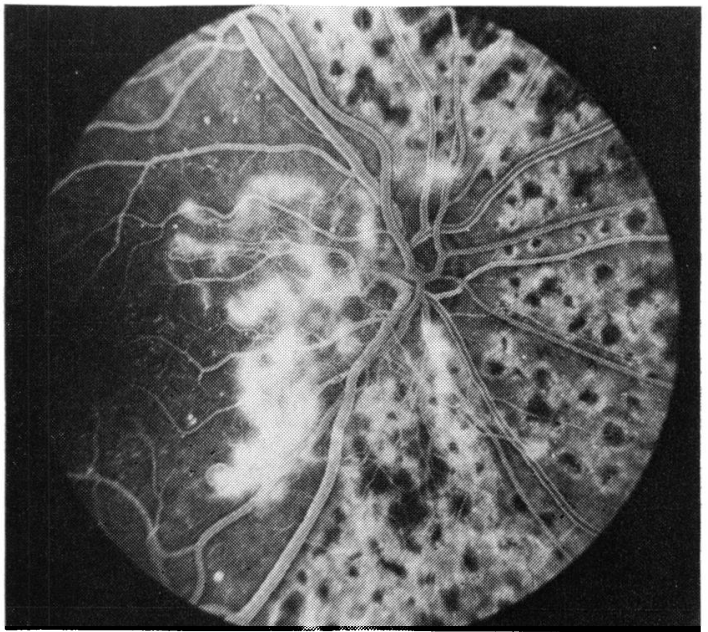

Fig. 6 Fluorescein angiogram showing the fundus of Fig. 46 months after successful completion of pregnancy. More extensive photocoagulation has been undertaken and there has been a slight reduction in neovascular tissue. 
Table 3a Patients developing vitreous haemorrhage after cessation of photocoagulation therapy

\begin{tabular}{lccc}
\hline & Pregnant & Nonpregnant & Men \\
\hline Both eyes & 4 & 10 & 9 \\
Treated eye & 2 & 5 & 5 \\
Control eye & 4 & 3 & 18 \\
Absent & 1 & 3 & 21 \\
Total no. of patients & 11 & 21 & 54 \\
\hline
\end{tabular}

Table 3b Comparison of vitreous haemorrhage events in the female groups

\begin{tabular}{|c|c|c|c|}
\hline & \multicolumn{2}{|c|}{$\begin{array}{l}\text { Vitreous haemorrhage events } \\
\text { ( } 1 \text { or more) }\end{array}$} & \multirow[b]{2}{*}{$\boldsymbol{P}$} \\
\hline & Present & Not present & \\
\hline \multicolumn{4}{|l|}{ Treated eyes } \\
\hline 'Pregnant' & 7 & 4 & 0.0344 \\
\hline 'Nonpregnant' & 5 & 16 & $\begin{array}{l}\text { Ho preg. } \\
\text { Nonpreg.* }\end{array}$ \\
\hline \multicolumn{4}{|l|}{ Control eyes } \\
\hline 'Pregnant' & 8 & 3 & 0.0396 \\
\hline 'Nonpregnant' & 7 & 14 & $\begin{array}{l}\text { Ho preg. } \\
\text { Nonpreg.* }\end{array}$ \\
\hline Pooled 'pregnant' eyes & 15 & 7 & \\
\hline Pooled 'nonpregnant' eyes & 12 & 30 & \\
\hline
\end{tabular}

*Ho preg. nonpreg. = pregnant not significantly greater than nonpregnant.

Table 4 Patients proceeding to blindness $(<6 / 60$ on the Snellen chart, at 2 successive 4-month visits) within 3 years

\begin{tabular}{llcccccc}
\hline & \multicolumn{2}{l}{ Pregnant } & \multicolumn{2}{l}{ Nonpregnant } & \multicolumn{2}{l}{ Men } \\
\cline { 2 - 7 } & $n$ & $\begin{array}{c}\% \\
\text { Total }\end{array}$ & $n$ & $\begin{array}{l}\% \\
\text { Total }\end{array}$ & $n$ & $\begin{array}{l}\% \\
\text { Total }\end{array}$ \\
\hline $\begin{array}{l}\text { Neither eye blind } \\
\text { Treated eye blind }\end{array}$ & 5 & 45.5 & 16 & 76.2 & 24 & 42.5 \\
$\begin{array}{l}\text { Control eye (only) } \\
\text { blind }\end{array}$ & 5 & 0 & 0 & 0 & 5 & 9.3 \\
$\begin{array}{l}\text { Both eyes blind } \\
\begin{array}{l}\text { All untreated eyes } \\
\text { blind }\end{array}\end{array}$ & 1 & 9 & 1 & 4.8 & 8 & 16.7 \\
\hline
\end{tabular}

proceeding to blindness within 3 years was significant in all but the late stages of the proliferative process (McNemar's modified $\chi^{2}$ test).

VISUAL ACUITY

No demonstrable significant difference between the retention of initial visual acuity in treated or control female eyes was demonstrated at any time (by Wilcoxon tests). When pregnant and nonpregnant patients were compared it was found that after 2 years there was a significant difference between the treated eyes of the nonpregnant and pregnant groups. The mean cumulative deterioration of visual acuity was greater in the pregnant group. The same result was also seen at 2 years when the control eyes of the above 2 groups were compared (Fig. 7).
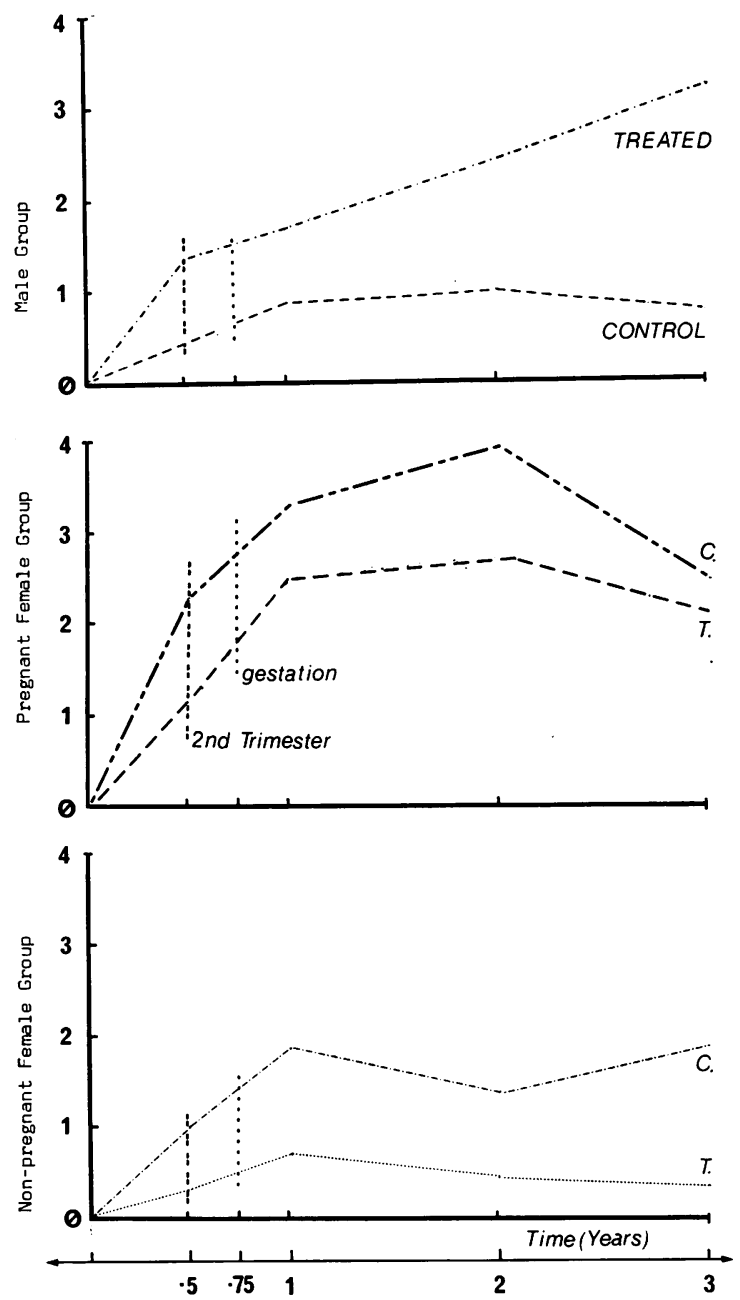

Fig. 7 Top: Three-year comparison of mean cumulative deterioration of visual acuity in male diabetics subjected to randomised uniocular panretinal photocoagulation for proliferative diabetic retinopathy involving the optic disc. Centre: Three-year comparison of mean cumulative deterioration of visual acuity between randomised eyes in pregnant diabetics ( $T=$ treated: $C=$ control eyes). Bottom: Three-year comparison of mean cumulative deterioration of visual acuity in nonpregnant diabetic women subjected to uniocular, randomised, panretinal photocoagulation (nulliparous or more than 5 years regular menstruation prior to assessment). 
Fig. 8 Mean cumulative deterioration of visual acuity contrast between all treated and 3-year period following control female eyes over the panretinal photocoagulation.

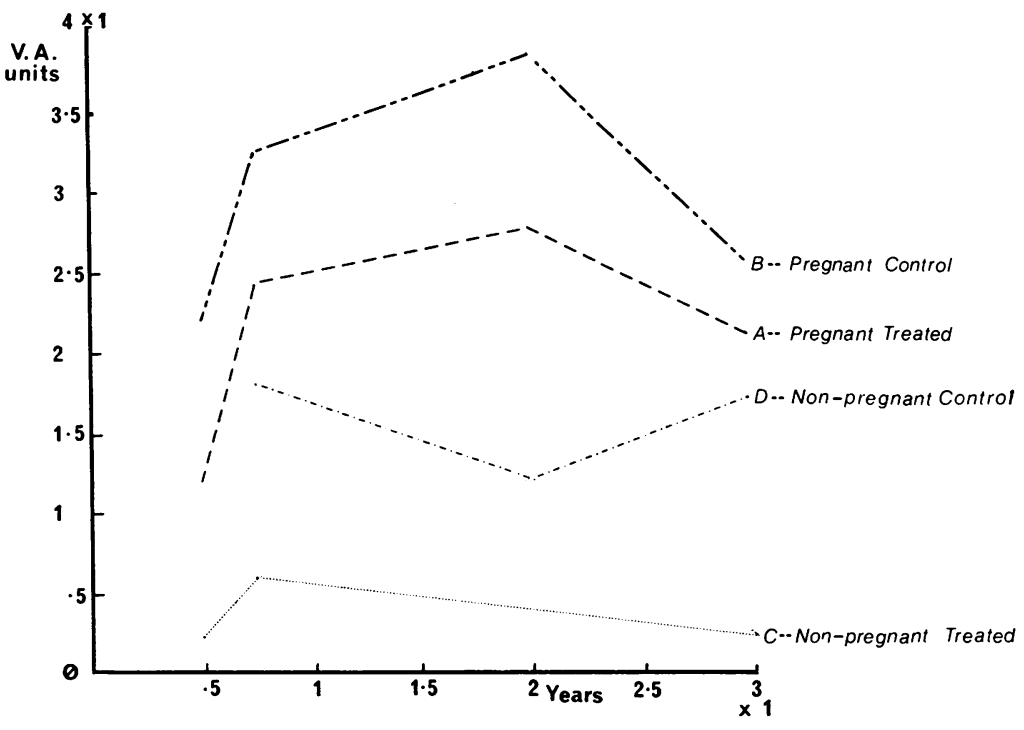

There was a statistically significant difference in mean cumulative deterioration of visual acuity between treated and untreated eyes (Table 5), in the female group studied (Fig. 8). This difference was found at all time-intervals measured, and is outlined below:

$\begin{array}{ll}\text { By Wilcoxon tests at } & \text { Between treated and control eyes } \\ 6 / 12 & \mathbf{P}=0.0297 \\ 9 / 12 & \mathbf{P}=0.0306 \\ 2 \text { years } & \mathbf{P}=0.0025 \\ 3 \text { years } & \mathbf{P}=0.0076\end{array}$

\section{Discussion}

No clear-cut conclusions regarding the effects exerted by pregnancy on proliferative retinal change in diabetes have been reached, because few centres have treated any significant number of patients, and the problem is further compounded by the fact that the natural history of the retinal process frequently spans a 9-month period. The outcome of pregnancy is certainly related, however, to the

Table 5 Comparison of mean cumulative deterioration (between the 3 groups) of visual acuity at 2 years (Kruskall-Wallis analysis of variance)

\begin{tabular}{llllll}
\hline \multicolumn{5}{c}{ Group } & \\
\cline { 3 - 5 } & & 1 & 2 & 3 & \\
\hline Treated eyes & $\mathrm{n}$ & 10 & 12 & 42 & $\mathbf{P}=0.0256$ \\
& rank & 19.3 & 39.25 & $33 \cdot 7$ & (poss. sig. diff) \\
Control eyes & $\mathrm{n}$ & 10 & 12 & 42 & $\mathbf{P}=0.0966$ \\
& rank & 24.5 & 41.3 & 31.7 & (poss. sig. diff) \\
\hline
\end{tabular}

presence of proliferative retinal change, as the severity of this change correlates quite closely with the presence of microangiopathy elsewhere in the body (especially the kidneys). ${ }^{7-9}$

It has not been possible clearly to elucidate an answer to the question, is pregnancy in some way exerting a trigger influence in the proliferative process? What does seem certain is that a considerable proportion of patients who show a progression of retinopathy during pregnancy will show regression after delivery. ${ }^{9-12}$ Unfortunately, this is clearly not the case in the patients who show proliferative, as opposed to background, retinal changes. This is particularly true in the group presently discussed, where the proliferative changes are the most sinister and vision-threatening of all, because neovascularisation of the optic disc is present.

The present series has shown that, even with a peripheral retinal ablation procedure utilising between 1200 and $2500,500 \mu \mathrm{m}$ spot-diameter impact-burns, a few beneficial effects are conferred. Significant improvement in neovascular status $(>50 \%)$ at the optic disc occurred in $63.6 \%$ of cases. Yet this did significantly reduce the frequency of severe vitreous haemorrhage $(\geqslant 2$ lines fall, in visual acuity, on the Snellen chart). Again, no beneficial or protective effect occurred within 3 years, when eventual visual acuity was examined. There was evidence of a statistically significant difference in mean cumulative deterioration of visual acuity between treated and control eyes over 1-2 years.

Any woman with the retinal vascular problems ensuing from optic disc neovascularisation runs a 
grave risk in assuming the added metabolic burden of pregnancy. In the later stages, hypertension and albuminuria may first appear. It is at this point in the pregnancy when proliferative change may appear to be contained by photocoagulation. Yet such reduction in the progressive nature of this process seems to have conferred little benefit visually to the patients examined in this series. If pregnancy is permitted to run its course, scrupulous care is necessary for the successful management of the diabetic. It is thus worthwhile to pursue the potentially protective effects of panretinal photocoagulation with a more extensive form of application (up to 6000 impact burns) than described in the patients from this series. It is the authors' considered opinion that therapeutic abortion and sterilisation are not justified for ophthalmic reasons.

Our thanks are due to Dr E. S. Rosen and Mr A. Stewart Scott for their support and permission to treat patients in their care.

\section{References}

${ }^{1}$ Taylor E, Dobree JH. Proliferative diabetic retinopathy: site and size of initial lesions. Br J Ophthalmol 1970; 54: 11-18.

'Beetham WP, Aiello IA, Balodimos MR, Koncz L. Ruby laser photocoagulation of early diabetic neovascular retinopathy. Preliminary report of a long-term controlled study. Arch Ophthalmol 1970; 83: 261-272.

${ }^{3}$ Caird FI, Burditt AF, Draper GJ. Diabetic retinopathy: a further study of prognosis for vision. Diabetes 1968; 17:121.

${ }^{4}$ Deckert T, Poulsen JE. Prognosis for juvenile diabetics with late diabetic manifestations. Acta Med Scand 1968; 183: 351 .

${ }^{5}$ Patz A, Berkow JW. Visual and systemic prognosis in diabetic retinopathy. Trans Am Acad Ophthalmol Otolaryngol 1968; 72: 253-258.

'Landesman R, Douglas RG, Bonses RW, MacDonald F. Toxaemias of Pregnancy. Pa Med 1953; 5513: 217-224.

${ }^{7}$ Beetham WP. Diabetic retinopathy in pregnancy. Transactions of the American Ophthalmology Society 1950; 48: 205.

${ }^{8}$ Janert H, Mohnike G, Georgi P. (1957). Ophthalmologische Diabetesstudien III. Retinopathia proliferans und Iridopathie, p. 110-119.

${ }^{9}$ White P. Pregnancy and diabetes: medical aspects. Med Clin North Am 1965; 49: 1015.

${ }^{10}$ Lawrence RD. Acute retinopathy without hyperiesis in diabetic pregnancy. Br J Ophthalmol 1948; 32: 328-465.

${ }^{11}$ Stevens JW, Page OC, Hare RL. Diabetes and pregnancy. Diabetes 1963; 12: 213-219.

${ }^{12}$ Laws HW, Harpur ER, Belmonte MM et al. (1966). A long-term study of retinal changes in the pre-puberty and puberty onset diabetes. Can J Ophthalmol 1966; 1: 104-111. ${ }^{13}$ Driscoll JJ, Gillespie L. Obstetrical considerations in diabetes in pregnancy. Med Clin North Am 1965; 49: 1053-67.

${ }^{14}$ Okun E, Johnston GP, Bonnuik K. Management of Diabetic Retinopathy. St Louis: Mosby, 1971; 44.

${ }^{15}$ Burt RL, Weaver RG. Proliferative diabetic retinopathy in pregnancy. Br J Obstet Gynaecol 1972; 40: 199-201.

${ }^{16}$ Kohner EM, Hamilton AM, Tunbridge WM. Diabetic retinopathy managed through a pregnancy. Proc $R$ Soc Med 1973; 66: 442-4.

${ }^{17}$ Hercules BL, Gayed II, Lucas SB, Jeacock J. Peripheral retinal ablation in the treatment of proliferative diabetic retinopathy: a three-year interim report on a randomised, controlled study using the argon laser. Br J Ophthalmol 1977; 61 : 555-563.

${ }^{18} \mathrm{~L}$ 'Esperance FA. An ophthalmic argon laser photocoagulation system: design, construction and laboratory investigations. Trans Am Ophthalmol Soc 1968; 66: 828-904. 